\title{
Unusual multiple cutaneous retiform hemangioendothelioma on forearm and neck misdiagnosed as angiosarcoma with metastasis
}

\author{
Bin-cai Pan ${ }^{1}$, Chun-hua Wang ${ }^{1}$, Gui-fang Huang ${ }^{1}$, Xiao-ying Tian ${ }^{2}$ and $\mathrm{Zhi} \mathrm{Li}^{3 *}$ \\ ${ }^{1}$ Department of Pathology, Guangdong Tongjiang Hospital, Nanguo East Road, Shunde district, Foshan 528300, China \\ ${ }^{2}$ School of Chinese Medicine, Hong Kong Baptist University 7, Baptist University Road, Kowloon Tong, Hong Kong, China \\ ${ }^{3}$ Department of Pathology, The First Affiliated Hospital, Sun Yat-sen university.58, Zhongshan Road II,Guangzhou 510080, China
}

\begin{abstract}
Retiform hemangioendothelioma $(\mathrm{RH})$ is extremely rare, and often involves the skin and subcutaneous tissues of distal extremities in young adults or children. Since its first description by Calonje in 1994, only a few primary multiple cases have been described in the literature. We present a case of unusual primary multiple RH on forearm and neck occurring in a 56 years old female patient. The patient presented with a slow-growing cutaneous plaque-like lesion on her left forearm, followed by another lesion at the site of neck for several years. In the skin biopsy examination, a diagnosis of angiosarcoma with cutaneous metastasis was made based on multiple lesions at different anatomic sites and vasoformative growth pattern with anastomosing channels under the microscopy. However, postoperative histological diagnosis of the lesion was primary multiple RH by thoroughly microscopical inspection and the presence of thin-walled interconnecting vascular channels arranged in a retiform pattern and absence of lymph node metastasis. Despite wide surgical excision with tumor-free margin, the tumor recurred at the neck 3 months after surgery. The second local excision was performed. The patient was on regular follow-up for 18 months without additional treatments. There was no sign of recurrence or lymph node metastasis. Due to its rarity, multiple RH might be erroneously interpreted as angiosarcoma with metastasis by those who were not familiar with this condition, or conduce to aggressive postoperative treatment. Therefore, thoroughly microscopical inspection and a long-term follow-up are helpful for surgeons and pathologists to obtain an accurate diagnosis and avoid clinical over-treatment.
\end{abstract}

\section{Introduction}

Retiform hemangioendothelioma $(\mathrm{RH})$ is a locally aggressive, rarely metastasizing vascular lesion characterized by low malignant potential and high rate of local recurrence. The tumor is uncommon, and often involves the skin and subcutaneous tissues of young adults or children [1]. Histologically, the tumor exhibits arborizing elongated blood vessels, hobnail monomorphic endothelial cells with scant cytoplasm and no significant atypia, prominent endovascular papillae with collagenous cores, and prominent lymphocytic infiltrate. According to these diagnostic criteria, to our knowledge, to date no more than 40 such cases have been described in the literature since its first description in 1994 by Calonje et al. [2-24]. RH does not appear to have any particular predilection site, but most of the reports were in the distal extremities, particularly the lower limbs. Nevertheless, the scalp, skull, and penis are involved in some cases [2, 10, 14, 16]. RH with multiple lesions has seldom been described. So far, only three case of multiple RH developed at different anatomic sites have been described in the literature $[4,7,14]$. However, due to its rarity, multiple RH may be erroneously interpreted as conventional angiosarcoma with multiple cutaneous or soft tissue metastases, resulting in an aggressive treatment strategy, including adjuvant radiotherapy or chemotherapy after surgical resection. Herein, we present a case of multiple RH arising on skin of forearm and neck of a middle-aged female patient. The clinical and histological features of this tumor, as well as differential diagnosis are discussed.

\section{Material and methods}

\section{Clinical presentation and management}

A 56-year old Chinese female patient was referred to our dermatology department for purple nodule and plaque developed on her forearm and neck. The patient had a history of a left forearm nodule that had progressively increased in size in 2009. At the local clinic, a preliminary clinical diagnosis of hemangioma was made, but the patient declined biopsy and histopathologic examination at that time. She was well until May 2012, when another purple plaque developed on her right neck. There were mild pain and swelling on her left forearm. Two weeks before admission to our hospital, the patient complained that the pain and tenderness of left forearm became worse and the right neck plaque increased in size. As a result, the patient was referred to our hospital for examination and treatment. There was no history of any trauma to arm and neck. Physical examination showed the patient had a mild soft tissues edema on her left forearm and mild pain was elicited upon

Correspondence to: Dr. Zhi Li, Department of Pathology, The First Affiliated Hospital, Sun Yat-sen University 58, Zhongshan Road II, Guangzhou 510080, China, Tel: (8620) 8733 0890; Fax: (8620) 87331780

Key words: Retiform hemangioendothelioma, recurrence, angiosarcoma, differential diagnosis

Received: February 01, 2017; Accepted: February 15, 2017; Published: February 17,2017 
pressure. The lesion on the forearm was a purple nodule, measuring $4.0 \mathrm{~cm}$ in diameter. The lesion of right neck was a $2.0 \mathrm{~cm}$ dusky red to brown plaque without distinctive borders. No ulceration or throbbing was noted on the lesions (Figure 1). There was no fever, weight loss and no palpable lymphadenopathy or organomegaly. The laboratory results, including blood count, differential, liver and renal function, were within the normal range. A CT scan of neck, chest and abdomen showed no pathologic findings, particularly no lymphadenopathy and metastatic diseases could be observed. A biopsy was performed on forearm lesion initially, histopathological examination showed vasoformative growth pattern with anastomosing channels. The lesions were preoperatively diagnosed as angiosarcoma with cutaneous metastasis. Both lesions on forearm and neck were gross total resected. Because the margin of the lesions was ill-defined, the surgical resection was extensive with negative margins. The postoperative phase was uneventful. After diagnosis, the patient received no radiotherapy or chemotherapy and was only on regular follow-up. However, 3 months after resection, a small nodule, measuring $1.0 \mathrm{~cm}$ in diameter, was observed at the site of original tumor location on neck. Consideration of tumor recurrence, the patient received the second excision. After surgery, the patient was on regular follow-up for 18 months without additional treatments. The patient has remained healthy, without evidence of lymph node or systemic disease. There was no sign of recurrence of tumor during the period of follow-up.

\section{Histological process}

The surgical specimens were routinely fixed in $10 \%$ neutral buffered formalin and embedded in paraffin. Four micrometer-thick sections were stained with $\mathrm{H} \& \mathrm{E}$ in our laboratory. Immunohistochemical assay was also performed using the ChemMate Envision/HRP Kit and antibodies were obtained from Dako Cytomation (Carpinteria, CA, USA) and Santa Cruz Biotechnology (Santa Cruz, CA, USA). The first monoclonal antibodies were against pan-cytokeratin (pan-CK, AE/ AE3), CD31, CD34, D2-40, HHV8, EMA, HMB-35, SMA and Ki-67 (MIB-1).

\section{Results}

Under microscopic examination, the surgical specimens from the lesions of forearm, neck and the recurred nodule showed similar histological findings in each. All of lesions were located in the superficial and deep dermis. The tumors were non-encapsulated and had infiltrative margin, subcutaneous fat and part of skeletal muscle were observed to be involved. The tumors were composed of multiple thin-walled interconnecting vascular channels arranged in a retiform pattern, resembling rete testis. The endothelial cells lining the vessels were single layered and showing monomorphic nuclei with scanty cytoplasm and distinctive hobnailed or "match-head" appearance. In

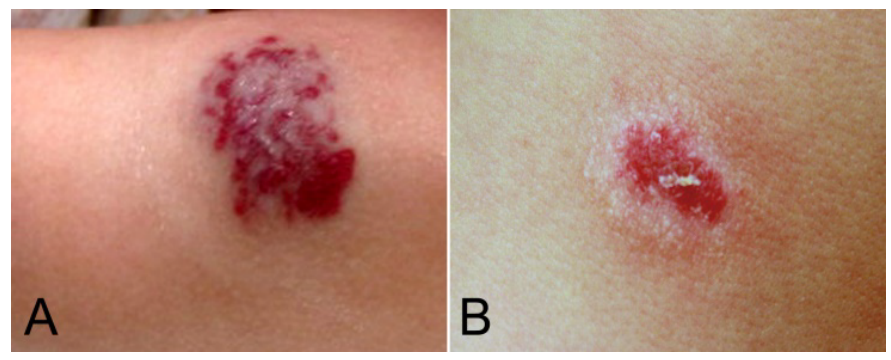

Figure 1. Gross appearance of multiple lesions on forearm and neck. (A) A purple nodule located on the left forearm, measuring $4.0 \mathrm{~cm}$ indiameter. (B) The lesion of right neck was a $2.0 \mathrm{~cm}$ duskyred to brown plaque without distinctive borders. focal areas, papillae projecting into lumen were noted. Those papillae had hyaline collagenous cores resembling to those seen in papillary intralymphatic angioendothelioma (Dabska tumor). The endothelial cells were minimally atypical, and mitoses were not identified. Stroma between the tumor cells showed prominent infiltration by lymphocytes (Figure 2). Immunohistochemistry stains done on these lesions were positivity for CD31 diffusely, but CD34 focally. Tumors were negative for D2-40, HHV-8, cytokeratin (AE1/AE3), EMA, HMB-45. SMA highlighted the vascular wall but was negative in the tumor cells. The

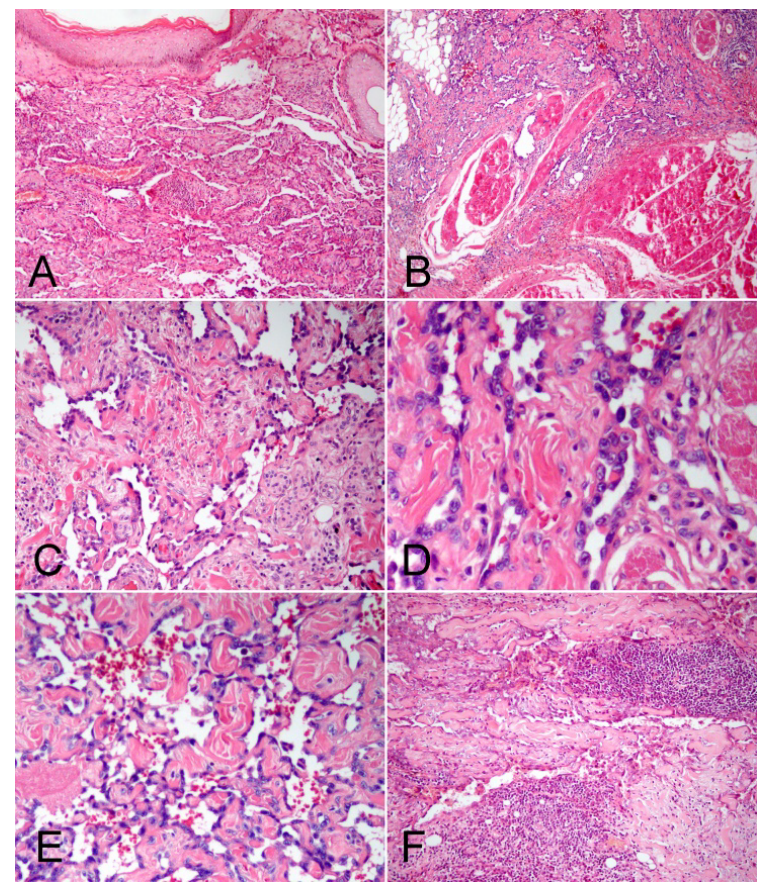

Figure 2. Photomicrographs of the forearm and neck lesions. (A) Microscopic examination demonstrated ill-definedneoplasm located in the superficial and deep dermis. (B) The tumor had infiltrativemargin, subcutaneousfat and part of skeletal muscle were observed to be involved. (C) The tumor was composed of multiple thin-walled interconnecting vascular channels arranged in a retiform pattern. (D) High-power photomicrograph demonstrated the characteristic "hobnail" appearance of the prominent endothelial cells. (E) In focal areas, papillae projecting into lumen were noted. Those papillae had hyaline collagenous cores resembling to those seen in papillary intralymphaticangioendothelioma (Dabska tumor) (F) Stroma between the tumor cells showed prominent infiltration by lymphocytes. (AB, F, H\&E staining with original magnification $\times 200$; C-E, H\&E staining with original magnification $\times 400$ ).

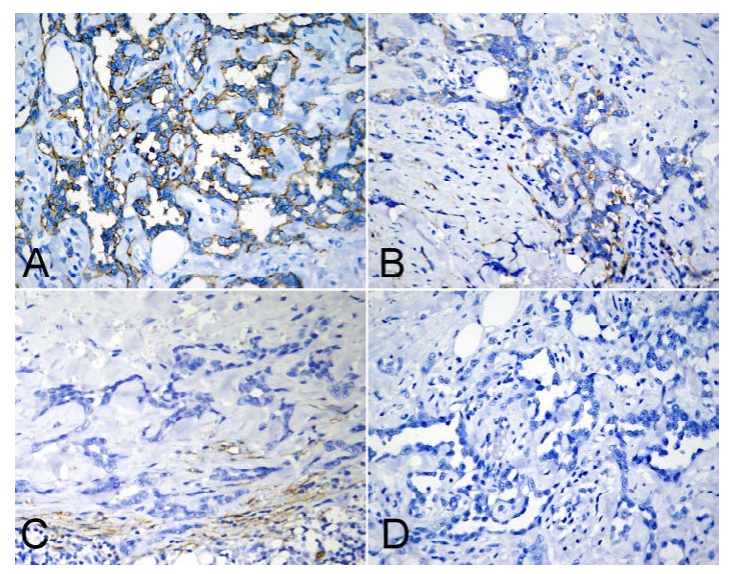

Figure 3. Immunohistochemical assay of tumor. (A) The tumor cells were observed to be positive for CD31 diffusely, but they were focally and weakly positive for CD34 (B). (C) Tumor cells were negative for D2-40 and HHV8 (D). (A-D, immunohistochemical staining with original magnification $\times 400$ ). 
Ki-67 labeling index of the lesions was low, accounting for $1 \%$ of the tumor (Figure 3). Based on the pathological findings, a final diagnosis of primary multiple $\mathrm{RH}$ with local recurrence was made according to WHO diagnostic criteria [1].

\section{Discussion}

Retiform hemangioendothelioma ( $\mathrm{RH})$, also termed as hobnail hemangioendothelioma, was first described in 1994 by Calonje and his colleagues where they presented cases occurring in 15 patients. In their originally reported cases, RH was regarded as "low-grade angiosarcoma" because this tumor recurred frequently with low metastatic rate [2]. Since then, a few reports of similar cases were published, most often occurring on the extremities of young adults [3-9]. In 2002, World Health Organization (WHO) classification of tumors of soft tissue and bone accepted $\mathrm{RH}$ as a rare entity, and identified it as an intermediate vascular neoplasm with putative borderline malignancy, as opposed to the benign angioma and the malignant angiosarcoma [25]. In 2013, the latest edition of WHO tumor classification ( $4^{\text {th }}$ edition) retains this tumor as a intermediate hemangioendothelioma, which includes $\mathrm{RH}$, papillary intralymphatic angioendothelioma, kaposiform, pseudomyogenic, and composite hemangioendotheliomas because of their intermediate biological behavior between benign hemangiomas and angiosarcomas [1]. The etiology of RH is still unknown. Several reports have proposed its association with lymphedema, previous radiation treatment, and non-epidermal malignant tumors $[2,5,8]$. An association between $\mathrm{RH}$ and human herpes virus 8 (HHV-8) has been reported in one case [8]. However, the certain pathogenesis of this tumor remains to be identified.

Since its first description by Calonje et al. no more than 40 , predominantly young to middle-aged cases have been described in the literature (Table 1). Of these 9 were children (under the 18 years old) and 30 were adults with female predilection (male: female $=12: 27$ ). It appears that RH may affect a wider age range, and all reported cases are from children to 78 years. $\mathrm{RH}$ does not show a preference for a specific anatomic site, but most of tumors involve the dermis and subcutaneous tissues of extremities (especially lower limbs and fingers). Tumor has also been described in other deeper locations, including trunk [8], breast [4] and bone [10]. Clinically, $\mathrm{RH}$ can present as a plaque, nodule, or exophytic mass with duration of disease ranging from 2 months to several years. Most of tumors grow slowly and occasionally shows bruise-like appearance with the tumor size ranging from 0.7 to $30 \mathrm{~cm}$ in greatest dimension. Most lesions are single, although only 4 cases of multiple tumors occurring in different anatomic sites have been described, including our case. Duke et al. reported the first case of multiple $\mathrm{RH}$ in the trunk, breast and extremities of a 30-yearold woman [4]. Also, Mentzel et al. reported multiple lesion in the extremities, scalp and ear in 40 and 61-year-old woman, respectively $[7,14]$. To our knowledge, our presenting case is rare case of primary multiple cutaneous $\mathrm{RH}$ in different anatomic sites. $\mathrm{RH}$ recurs in almost half of the cases within 2 to 27 months after initial excision [2-24]. Because of the infiltrative growth pattern of $\mathrm{RH}$ it is difficulty to achieve tumor-free margins, which likely contributes to the high recurrence rate although several cases performed wide local excision with negative margin [14]. So far, only three cases of RH have developed metastases to regional lymph nodes which indicate a very aggressive biological behavior $[2,12,19]$. However, clinical follow-up ranged from 4 months to 22 years, no distant metastasis has been observed. In previously reported cases, two patients with $\mathrm{RH}$ died after tumor excision. Zhang et al. reported an unusual case of $\mathrm{RH}$ presenting aggressive and lethal clinical course. The patient had rapid tumor local recurrence 3 months after excision and died of disease 6 months after excision [14]. Also, Albertini et al. reported a lethal RH case occurring in a 6-year-old girl, in which the patient died of hypovolemic shock 8 months after surgery because of pre-existed diffuse lymphangiomatosis [18]. Those lethal cases indicate that $\mathrm{RH}$ may exhibit more aggressive behavior than originally described by Calonje [2].

Since cases of RH are so rare, the diagnosis should be only made by strict histological and clinical manifestation. According to the WHO criteria, $\mathrm{RH}$ is characterized by multiple interconnecting arborizing blood vessels arranged in a retiform pattern, lined by monomorphic "hobnail" or "matchstick" endothelial cells that showed minimal cytologic atypia and no mitotic figures. Immunohistochemically, tumor cells are positive for vascular endothelial markers such as VonWillebrand factor, CD34 and CD31 are commonly positive in most of tumors at varying intensities in each case, which help identify and diagnose the tumor as a type of vascular neoplasms. But only a few cases of RH may express podoplanin (D2-40) and vascular endothelial growth factor receptor-3 (VEGR-3), markers of endothelium of lymphatic vessels $[13,26]$, which indicates that $\mathrm{RH}$ is a vascular entity and usually does not have lymphatic differentiation. In the present case, irregular vascular channels lined by endothelial cells with a "hobnail" appearance, papillary projections with a central hyaline core and scarce mitotic figures help identify the tumor as a "hobnail" hemangioendothelioma. A prominent stromal lymphocytic infiltrate and immuno-negativity of D2-40 point to a certain diagnosis of $\mathrm{RH}$.

Multiple RH shows distinctive features that the patient develops multiple tumors at different anatomic sites. In our case, multiple cutaneous lesions could be observed on forearm and neck, which might be regarded as secondary foci of tumor, gave the histological diagnosis of angiosarcoma with cutaneous metastasis. Since the RH is rare, the interconnecting or anastomosing vascular channels might be erroneously interpreted conventional angiosarcoma by those who were not familiar with this condition. This might be the reason that led to the misdiagnosis of angiosarcoma with cutaneous metastasis. However, cutaneous angiosarcoma usually has dismal prognosis with very high incidence of recurrence and metastasis and high mortality rate. Although angiosarcoma and RH have in common an infiltrative pattern, the vascular spaces formed in angiosarcoma tend to be more irregular and jagged than those in RH. The cytologic atypia, multilayering, and mitotic figures are more remarkable in angiosarcoma, even in well-differentiated angiosarcoma [27]. But the overall appearance of $\mathrm{RH}$ is that of a monotonous neoplasm with hobnail appearance and very little cytologic atypia. In addition, the presence of a prominent inflammatory cell infiltrate is also a helpful clue for diagnosis of $\mathrm{RH}$, although some cases of angiosarcoma can also exhibit this appearance. In our case, the non-contiguous nature of the tumors and the absence of cytologic atypia and lymph node or internal organ involvement strongly support the diagnosis of primary multiple $\mathrm{RH}$ rather than angiosarcoma with metastasis. However, $\mathrm{RH}$ with multiple lesions at different anatomic sites does not imply a worse prognosis of tumor. Duke reported a multiple $\mathrm{RH}$ had no recurrence 10 years after surgery without any adjuvant treatment [4]. Therefore, multiple RH may not certainly conduce to more aggressive clinical treatment, including postoperative radiotherapy or chemotherapy. A postoperative longterm follow-up should be performed as an appropriate scheme to supervise the locoregional recurrence.

In addition, two particular types of vascular lesions with hobnail endothelial cells, targetoid hemosiderotic hemangioma (hobnail hemangioma) and papillary intralymphatic angioendothelioma 
Table 1. The clinicopathological characteristics of retiform hemangioendothelioma described in present and previous reports.

\begin{tabular}{|c|c|c|c|c|c|c|c|c|}
\hline Case & Author (yr.) & $\begin{array}{l}\text { Age (yrs)/ } \\
\text { Gender }\end{array}$ & Location/size & $\begin{array}{l}\text { Multiple } \\
\text { site }\end{array}$ & Treatment & Recurrence & Metastasis & Outcome \\
\hline $1-15$ & Calonje E (1994) [2] & 9-78 / 9F, 6M & $\begin{array}{l}\text { Lower limbs (6), upper limbs (4), } \\
\text { trunk (3), penis (1), scalp (1)/2.0- } \\
9.0 \mathrm{~cm}\end{array}$ & no & WLE & yes $(8 / 15)$ & $\begin{array}{l}1 / 15 \text { (regional } \\
\mathrm{LN})\end{array}$ & $\begin{array}{l}\text { A median follow-up of } 7.25 \text { years in } 14 \\
\text { cases, no tumor-related deaths }\end{array}$ \\
\hline 16 & Fukunaga M (1996) [3] & $75 / \mathrm{F}$ & Lower thigh $/ 3.5 \mathrm{~cm}$ & no & SE & yes & no & Local recurrence 27 months after excision \\
\hline 17 & Duke D (1996) [4] & $30 / \mathrm{F}$ & Trunk, breast and extremities & yes & SE & no & no & $\begin{array}{l}\text { Live and no recurrence after } 10 \text { years } \\
\text { following-up }\end{array}$ \\
\hline $18-19$ & Dufau JP (1997) [5] & $29-40 / 2 \mathrm{~F}$ & Lower $\operatorname{limb} / 1.0-1.5 \mathrm{~cm}$ & no & SE & no & no & $\begin{array}{l}\text { Live and no recurrence after } 5 \text { years } \\
\text { following-up }\end{array}$ \\
\hline 20 & Sanz-Trelles A (1997) [6] & $11 / \mathrm{M}$ & Toe $/ 1.5 \mathrm{~cm}$ & no & SE & no & no & $\begin{array}{l}\text { Live and no recurrence after } 4 \text { years } \\
\text { following-up }\end{array}$ \\
\hline 21 & Mentzel T (1997) [7] & $40 / \mathrm{F}$ & $\begin{array}{l}\text { Right great toe and right lower } \\
\text { leg/ND }\end{array}$ & yes & SE & yes & no & Local recurrence after excision \\
\hline 22 & Schommer M (2000) [8] & $73 / \mathrm{F}$ & Trunk $/ 30 \mathrm{~cm}$ & no & SE & yes & no & Local recurrence 2 years after excision \\
\hline 23 & El Darouti M (2000) [9] & $32 / \mathrm{F}$ & Left upper thigh $/ 3.5 \mathrm{~cm}$ & no & SE & no & no & $\begin{array}{l}\text { Live and no recurrence after } 18 \text { months } \\
\text { following-up }\end{array}$ \\
\hline 24 & Aditya GS (2003) [10] & $36 / \mathrm{M}$ & Skull bone $/ 5.0 \mathrm{~cm}$ & no & NA & NA & NA & NA \\
\hline 25 & Tan D (2005) [11] & $19 / \mathrm{F}$ & Lower $\operatorname{limb} / 4.5 \mathrm{~cm}$ & no & WLE & no & no & $\begin{array}{l}\text { Live and no recurrence after } 14 \text { months } \\
\text { following-up }\end{array}$ \\
\hline 26 & Bhutoria B (2009) [12] & $35 / \mathrm{F}$ & mons pubis $/ 4.0 \mathrm{~cm}$ & no & SE & yes & $\begin{array}{l}\text { yes (inguinal } \\
\text { lymph node) }\end{array}$ & Local recurrence 2 years after excision \\
\hline 27 & Emberger M (2009) [13] & $17 / \mathrm{M}$ & Back $/ 2.5 \mathrm{~cm}$ & no & WLE & no & no & $\begin{array}{l}\text { Live and no recurrence after } 3 \text { years } \\
\text { following-up }\end{array}$ \\
\hline 28 & Zhang G (2010) [14] & $61 / \mathrm{F}$ & Scalp and ear $/ 8.0$ and $2.0 \mathrm{~cm}$ & yes & WLE & yes & no & $\begin{array}{l}\text { Local recurrence } 3 \text { months after excision } \\
\text { and die of disease } 6 \text { months after excision }\end{array}$ \\
\hline 29 & Aydingöz IE (2010) [15] & $60 / \mathrm{F}$ & Left ankle $/ 6.0 \mathrm{~cm}$ & no & WLE & no & no & $\begin{array}{l}\text { Live and no recurrence after } 2 \text { years } \\
\text { following-up }\end{array}$ \\
\hline 30 & Hirsh AZ (2010) [16] & $44 / \mathrm{M}$ & Scrotum/NA & no & $\mathrm{RT}+\mathrm{CT}$ & no & no & $\begin{array}{l}\text { Live and no recurrence after } 36 \text { months } \\
\text { following-up }\end{array}$ \\
\hline 31 & Keiler SA (2011) [17] & $11 / \mathrm{F}$ & Left fourth finger $/ 0.7 \mathrm{~cm}$ & no & MMS & no & no & $\begin{array}{l}\text { Live and no recurrence after } 5 \text { months } \\
\text { following-up }\end{array}$ \\
\hline 32 & Albertini AF (2011) [18] & $6 / F$ & Neck/ NA & no & SE & yes & no & $\begin{array}{l}\text { Died of hypovolemic shock } 8 \text { months after } \\
\text { surgery }\end{array}$ \\
\hline 33 & O'Duffy F (2012) [19] & $18 / \mathrm{M}$ & left pinna rim/NA & no & $\mathrm{SE}+\mathrm{RT}$ & yes & $\begin{array}{l}\text { Yes (parotid } \\
\text { lymph node) }\end{array}$ & $\begin{array}{l}\text { Live and no recurrence after } 16 \text { months } \\
\text { following-up }\end{array}$ \\
\hline 34 & Choi WK (2012) [20] & $20 / \mathrm{M}$ & Left index finger $/ 1.5 \mathrm{~cm}$ & no & SE & yes & no & Local recurrence 2 months after surgery \\
\hline 35 & Couceiro J (2013) [21] & $42 / \mathrm{F}$ & Small finger $/ 1.0 \mathrm{~cm}$ & no & SE & no & no & $\begin{array}{l}\text { Live and no recurrence after } 4 \text { months } \\
\text { following-up }\end{array}$ \\
\hline 36 & Mota A (2013) [22] & $26 / \mathrm{F}$ & Right flank $/ 3.0 \mathrm{~cm}$ & no & SE & no & no & NA \\
\hline 37 & Al-Faky YH (2014) [23] & $9 / \mathrm{F}$ & Right medial canthus $/ 0.8 \mathrm{~cm}$ & no & SE & no & no & $\begin{array}{l}\text { Live and no recurrence after } 6 \text { years } \\
\text { following-up }\end{array}$ \\
\hline 38 & Zheng LQ (2014) [24] & $71 / \mathrm{F}$ & Right foot $/ 12.0 \mathrm{~cm}$ & no & SE & yes & no & Local recurrence 6 months after surgery \\
\hline 39 & Present case & $56 / \mathrm{F}$ & $\begin{array}{l}\text { Left forearm and right neck } / 4.0 \\
\mathrm{~cm} \text { and } 2.0 \mathrm{~cm}\end{array}$ & yes & WLE & yes & no & Local recurrence 3 months after surgery \\
\hline
\end{tabular}

(PILA, Dabska tumor) should also be distinguished from RH. Hobnail hemangiomas have a distinctive clinical appearance characterized by a small solitary lesion, consisting of a brown to violaceous papule surrounded by a thin pale area and a peripheral ecchymotic ring, due to hemosiderin depositions. The tumors are located more superficially, lack a retiform architecture, and have hobnail endothelial cells that are mainly seen in the vessels near the surface [28]. PILA may also be confused with the $\mathrm{RH}$, because of presence of "hobnail" cells or irregular papillary projections in vascular channels. Some researchers considered that PILA has a close histological and perhaps pathogenetic relationship to $\mathrm{RH}$, and $\mathrm{RH}$ may represent the adult counterpart of PILA [2]. However, the cavernous lymphangioma-like appearance of PILA contrasts with the retiform architecture of RH. The intraluminal papillary tufts with hyaline cores that constitute one of the more distinctive features of PILA are infrequent or only poorly developed in $\mathrm{RH}$.

In contrast to PILA of low local recurrence or metastasis [29], multiple local recurrences are frequent in RH. Due to its high incidence of local recurrence, the treatment of choice for RH is a wide surgical excision with histopathological tumor-free margins and long-term follow-up is essential $[1,11,13-15]$. Radiotherapy has been reported to be successfully administered as adjuvant treatment for local as well as regional nodal $\mathrm{RH}$ recurrences $[16,19]$. Recently, low-dose cisplatin and moderate radiotherapy has also been performed on a patient with unresectable RH [16]. But the efficacy of chemotherapy on recurred $\mathrm{RH}$ or RH with lymph node metastasis is still unclear. More treatment strategies of this uncommon tumor remain under investigation.

In conclusion, only a few cases of primary multiple RH have been reported in the literature. Our additive case is also presented for its rarity of multiple sites. The diagnosis of multiple $\mathrm{RH}$ is difficult and should be made cautiously. Multiple RH does not imply unfavorable prognosis and conduce to a more aggressive treatment certainly. Besides confirmation by strict histological criteria, a long-term followup should be performed to supervise the locoregional recurrence. 


\section{Consent}

Written informed consent was obtained from the patient for publication of this case report and any accompanying images. A copy of the written consent is available for review by the Editor-in-Chief of this journal.

\section{Competing interests}

The authors declare that we have no competing interests.

\section{References}

1. Calonje JE (2013) Retiform hemangioendothelioma. In World Health Organization Classification of Tumours of soft tissue and bone. Edited by Fletcher CDM, Bridge JA, Hogendoorn PCW, Mertens F. Lyon: IARC press. 147-148.

2. Calonje E, Fletcher CD, Wilson-Jones E, Rosai J (1994) Retiform hemangioendothelioma. A distinctive form of low-grade angiosarcoma delineated in a series of 15 cases. Am J Surg Pathol 18:115-125. [Crossref]

3. Fukunaga M, Endo Y, Masui F, Yoshikawa T, Ishikawa E, et al. (1996) Retiform haemangioendothelioma. Virchows Arch 428: 301-304. [Crossref]

4. Duke D, Dvorak A, Harris TJ, Cohen LM (1996) Multiple retiform hemangioendotheliomas. A low-grade angiosarcoma. Am J Dermatopathol 18: 606610. [Crossref]

5. Dufau JP1, Pierre C, De Saint Maur PP, Bellavoir A, Gros P (1997) [Retiform hemangioendothelioma]. Ann Pathol 17: 47-51. [Crossref]

6. Sanz-Trelles A, Rodrigo-Fernandez I, Ayala-Carbonero A, Contreras-Rubio F (1997) Retiform hemangioendothelioma. A new case in a child with diffuse endovascular papillary endothelial proliferation. J Cutan Pathol 24: 440-444. [Crossref]

7. Mentzel T, Stengel B, Katenkamp D (1997) Retiform hemangioendothelioma. Clinicopathologic case report and discussion of the group of low malignancy vascular tumors. Pathologe 18:390-394. [Crossref]

8. Schommer M, Herbst RA, Brodersen JP, Kiehl P, Katenkamp D, et al. (2000) Retiform hemangioendothelioma: another tumor associated with human herpesvirus type 8 ? $J$ Am Acad Dermatol 42: 290-292. [Crossref]

9. El Darouti M, Marzouk SA, Sobhi RM, Bassiouni DA (2000) Retiform hemangioendothelioma. Int J Dermatol 39: 365-368. [Crossref]

10. Aditya GS, Santosh V, Yasha TC, Shankar SK (2003) Epithelioid and retiform hemangioendothelioma of the skull bone-report of four cases. Indian J Pathol Microbiol 46: 645-649. [Crossref]

11. Tan D1, Kraybill W, Cheney RT, Khoury T (2005) Retiform hemangioendothelioma: a case report and review of the literature. J Cutan Pathol 32: 634-637. [Crossref]

12. Bhutoria B, Konar A, Chakrabarti S, Das S (2009) Retiform hemangioendothelioma with lymph node metastasis: a rare entity. Indian J Dermatol Venereol Leprol 75: 6062. [Crossref]
13. Emberger M, Laimer M, Steiner H, Zelger B (2009) Retiform hemangioendothelioma: presentation of a case expressing D2-40. J Cutan Pathol 36: 987-990. [Crossref]

14. Zhang G, Lu Q, Yin H, Wen H, Su Y, et al. (2010) A case of retiformhemangioendothelioma with unusual presentation and aggressive clinical features. Int $J$ Clin Exp Pathol 3: 528-533. [Crossref]

15. Aydingöz IE, Mansur AT, Celasun B (2010) Retiform hemangioendothelioma presenting as a hyperhidrotic tumor. Int J Dermatol 49: 1076-1077. [Crossref]

16. Hirsh AZ, Yan W, Wei L, Wernicke AG, Parashar B (2010) Unresectable retiform hemangioendothelioma treated with external beam radiation therapy and chemotherapy: a case report and review of the literature. Sarcoma 756246.

17. Keiler SA, Honda K, Bordeaux JS (2011) Retiform hemangioendothelioma treated with Mohs micrographic surgery. J Am Acad Dermatol 65: 233-235. [Crossref]

18. Albertini AF, Brousse N, Bodemer C, Calonje E, Fraitag S (2011) Retiform hemangioendothelioma developed on the site of an earlier cystic lymphangioma in a six-year-old girl. Am J Dermatopathol 33: e84-87. [Crossref]

19. O’Duffy F, Timon C, Toner M (2012) A rare angiosarcoma: retiform haemangioendothelioma. J Laryngol Otol 126: 200-202. [Crossref]

20. Choi WK, Lee SH, Oh SA, Kang DH (2012) Retiform hemangioendothelioma on the finger. Arch Plast Surg 39: 80-82. [Crossref]

21. Couceiro J, Sanders S, Cobb M, Manon-Matos Y, Banegas R (2013) Retiform hemangioendothelioma of the finger: a case report. Hand Surg 18: 439-441. [Crossref]

22. Mota A, Argenziano G, Zalaudek I, Piana S, Longo C, et al. (2013) Clinical, dermoscopic and histopathologic findings of retiform hemangioendothelioma. Dermatol Pract Concept 3:11-14. [Crossref]

23. Al-Faky YH1, Al-Mosallam AR, Al-Rikabi AC, Al-Sohaibani MO (2014) Media canthus retiform hemangioendothelioma. Indian J Ophthalmol 62: 491-493. [Crossref]

24. Zheng LQ, Han XC, Huang Y, Fan JY (2014)Cutaneous Retiform Hemangioendothelioma on the Right Foot with an Unusual Clinicopathological Feature. Am J Dermatopathol 36: 757-759.

25. Calonje JE (2002) Retiform hemangioendothelioma. In World Health Organization Classification of Tumours of soft tissue and bone. Edited by Fletcher CDM, Unni KK, Mertens F. Lyon: IARC press 165-166.

26. Parsons A, Sheehan DJ, Sangueza OP (2008) Retiform hemangioendotheliomas usually do not express D2-40 and VEGFR-3. Am J Dermatopathol 30: 31-33. [Crossref]

27. Weiss SW, Antonescu CR, Deyrup AT (2013) Angiosarcoma of soft tissue. In World Health Organization Classification of Tumours of soft tissue and bone. Edited by Fletcher CDM, Bridge JA, Hogendoorn PCW, Mertens F. Lyon: IARC press 156-158.

28. Mentzel T, Partanen TA, Kutzner H (1999) Hobnail hemangioma ("targetoid hemosiderotic hemangioma"): clinicopathologic and immunohistochemical analysis of 62 cases. J Cutan Patho 26:279-286. [Crossref]

29. Fanburg-Smith JC, Michal M, Partanen TA, Alitalo K, Miettinen M (1999) Papillary intralymphatic angioendothelioma (PILA): a report of twelve cases of a distinctive vascular tumor with phenotypic features of lymphatic vessels. Am J Surg Pathol 23: 1004-1010. [Crossref]

Copyright: (C2017 Pan B. This is an open-access article distributed under the terms of the Creative Commons Attribution License, which permits unrestricted use, distribution, and reproduction in any medium, provided the original author and source are credited. 